\title{
EAR AND AERODIGESTIVE TRACT FOREIGN BODY IN CHILDREN IN A TERTIARY CARE CENTRE IN NORTH INDIA
}

\author{
Sajeev Kumar Digraํ, Kamal Kishore2, Kishour Kumar Digra³, Subhash Singh Slathia ${ }^{4}$ \\ ${ }^{1}$ Associate Professor, Department of Paediatrics, Government Medical College, Jammu. \\ ${ }^{2}$ Assistant Professor, Department of ENT, Government Medical College, Jammu. \\ 3Medical Officer, CHC, Jourian, Jammu. \\ ${ }^{4}$ Consultant, Department of Paediatrics, Government Medical College, Jammu.
}

\section{ABSTRACT}

\section{BACKGROUND}

A foreign body (FB) is an object or substance foreign to the location where it is found. FBs in the ear, nose, and throat are a common problem frequently encountered in both children and adults.

The objective of the study is to analyse foreign bodies in terms of type, site, age, gender distribution and method of removal.

\section{MATERIALS AND METHODS}

This retrospective descriptive study was performed in a tertiary care hospital in Jammu. The study period was from $1^{\text {st }}$ November 2014 to $31^{\text {st }}$ October 2015. The information was obtained from hospital record books.

\section{RESULTS}

A total of 116 patients had foreign bodies in the ear, nose, or throat; 60 (51.7\%) were male and 56 (48.3\%) were female. Majority (72) were below 5 years of age and 44 were above 5 years. Youngest child was 6 months old and the eldest was of 14 years. 87 $(75 \%)$ children belonged to rural area. Majority $(62.06 \%, 72)$ of children reported with foreign body in throat/oesophagus followed by $28(24.13 \%)$ children with history of foreign body in ear. 8 (6.89\%) cases each of foreign body in nose and bronchus were observed.

\section{CONCLUSION}

Foreign bodies in throat/oesophagus were found more frequently in children followed by in ear. Most of the foreign bodies can be easily removed in emergency room or outpatient department.

\section{KEYWORDS}

Foreign Body, Ear, Nose, Throat, Paediatrics.

HOW TO CITE THIS ARTICLE: Digra SK, Kishore K, Digra KK, et al. Ear and aerodigestive tract foreign body in children in a tertiary care centre in North India. J. Evolution Med. Dent. Sci. 2017;6(87):5997-6000, DOI: 10.14260/jemds/2017/1304

\begin{tabular}{ll}
\hline BACKGROUND & and absence of watchful caregivers. ${ }^{3}$ Foreign body aspiration \\
A foreign body (FB) is an object in a region it is not meant to & is common in children and requires early diagnosis and \\
be, where it can cause harm by its mere presence if & treatment. Delay in management can lead to serious \\
immediate medical attention is not sought. ${ }^{1}$ It can be found in & complications and even death. ${ }^{4}$
\end{tabular}
the ear, nose and throat (ENT) region. Foreign body may be classified as animate (living) and inanimate (non-living). The inanimate foreign bodies can further be classified as organic or inorganic and hygroscopic (hydrophilic) or nonhygroscopic (hydrophobic). ${ }^{2}$ The presence of foreign body in the ear, nose and throat region is one of the most common causes of otolaryngological emergencies. Foreign bodies can be introduced spontaneously or accidentally in both adults and children. Generally, foreign bodies are more common in younger children. This may be due to various factors such as curiosity to explore orifices, imitation, boredom, playing, mental retardation, insanity, and attention deficit hyperactivity disorder, along with availability of the objects

'Financial or Other Competing Interest': None.

Submission 21-07-2017, Peer Review 17-10-2017,

Acceptance 24-10-2017, Published 30-10-2017.

Corresponding Author:

Dr. Sanjeev Kumar Digra

\#24-A, Pragati Nagar,

Upper Barnai, Jammu-181205,

Jammu and Kashmir.

E-mail: sanjeevahsaas@yahoo.co.in

DOI: $10.14260 /$ jemds $/ 2017 / 1304$

\section{Objectives}

The objective of this study was to analyse foreign bodies in ear, nose and throat region in terms of type, site, age, and gender distribution and method of removal.

\section{MATERIALS AND METHODS}

This retrospective descriptive study was performed in the departments of Paediatrics and ENT in a tertiary care hospital in the Government Medical College, Jammu. The study population included the number of paediatric patients with history of foreign body lodgement in ear, nose and throat region who presented in the outpatient department (OPD) or in the emergency room (ER) of both the departments during the 1-year study period (1 ${ }^{\text {st }}$ November 2014 to $31^{\text {st }}$ October 2015). The data was obtained from the hospital record books and then analysed in terms of type, site and method of removal of foreign bodies and the demographic profile of patients.

\section{RESULTS}

During the study period, a total of 116 patients comprising of $60(51.7 \%)$ males and 56 (48.3\%) females reported with 
history of foreign bodies in the ear, nose, or throat. Majority (72) were below 5 years of age and 44 were above 5 years. Youngest child was 6 months old and the eldest was 14 years.

\section{Foreign Bodies in the throat or oesophagus}

Majority $(62.06 \%, 72)$ of children reported with foreign body in throat or oesophagus which included coin in 50 cases followed by small battery in 16 cases and chicken bone in 3 . However, no foreign body was found in 3 cases. Rigid oesophagoscopy was done in all the cases to remove foreign bodies.

\section{Foreign Bodies in the Ear}

Total of $28(24.13 \%)$ children reported with history of foreign body in ear which included pea in 8 cases, eraser in 8 cases followed by 4 cases of pebble in ear and 2 cases each of remote button, maize seed and peanut. All of these were removed with the help of Jobson Horne Probe, forceps or ear hook. No foreign body was detected in two cases.

\section{Foreign Bodies in the Nose}

Total of $8(6.89 \%)$ cases of foreign body in nose were observed. In nose, 3 cases each of button, peanut and 2 of watch cell were observed. All of these were removed with the help of Eustachian catheter.

\section{Foreign Bodies in Bronchus}

Total of 8 (6.89\%) cases of foreign body in bronchus were observed. Bits of almond and berry fruit were detected in 3 cases each and a small plastic whistle and peanut was detected in 1 case each. All of these foreign bodies were removed by rigid bronchoscopy.

\begin{tabular}{|c|c|c|c|}
\hline $\begin{array}{c}\text { Site of } \\
\text { Foreign Body }\end{array}$ & $\begin{array}{c}\text { Type of } \\
\text { Foreign Body }\end{array}$ & Number & Total No. \\
\hline \multirow{4}{*}{$\begin{array}{c}\text { Throat/ } \\
\text { Oesophagus }\end{array}$} & Coin & 50 & \multirow{4}{*}{72} \\
\hline & Battery & 16 & \\
\hline & Chicken Bone & 03 & \\
\hline & None & 03 & \\
\hline \multirow{7}{*}{ Ear } & Eraser & 08 & \multirow{7}{*}{28} \\
\hline & Pea & 08 & \\
\hline & Pebble & 04 & \\
\hline & Remote Button & 02 & \\
\hline & Maize Seed & 02 & \\
\hline & Peanut & 02 & \\
\hline & None & 02 & \\
\hline \multirow{3}{*}{ Nose } & Button & 03 & \multirow{3}{*}{08} \\
\hline & Peanut & 03 & \\
\hline & Watch Cell & 02 & \\
\hline \multirow{4}{*}{ Bronchus } & Bits of Almond & 03 & \multirow{4}{*}{08} \\
\hline & Bits of Berry & 03 & \\
\hline & $\begin{array}{l}\text { Small Plastic } \\
\text { Whistle }\end{array}$ & 01 & \\
\hline & Peanut & 01 & \\
\hline
\end{tabular}
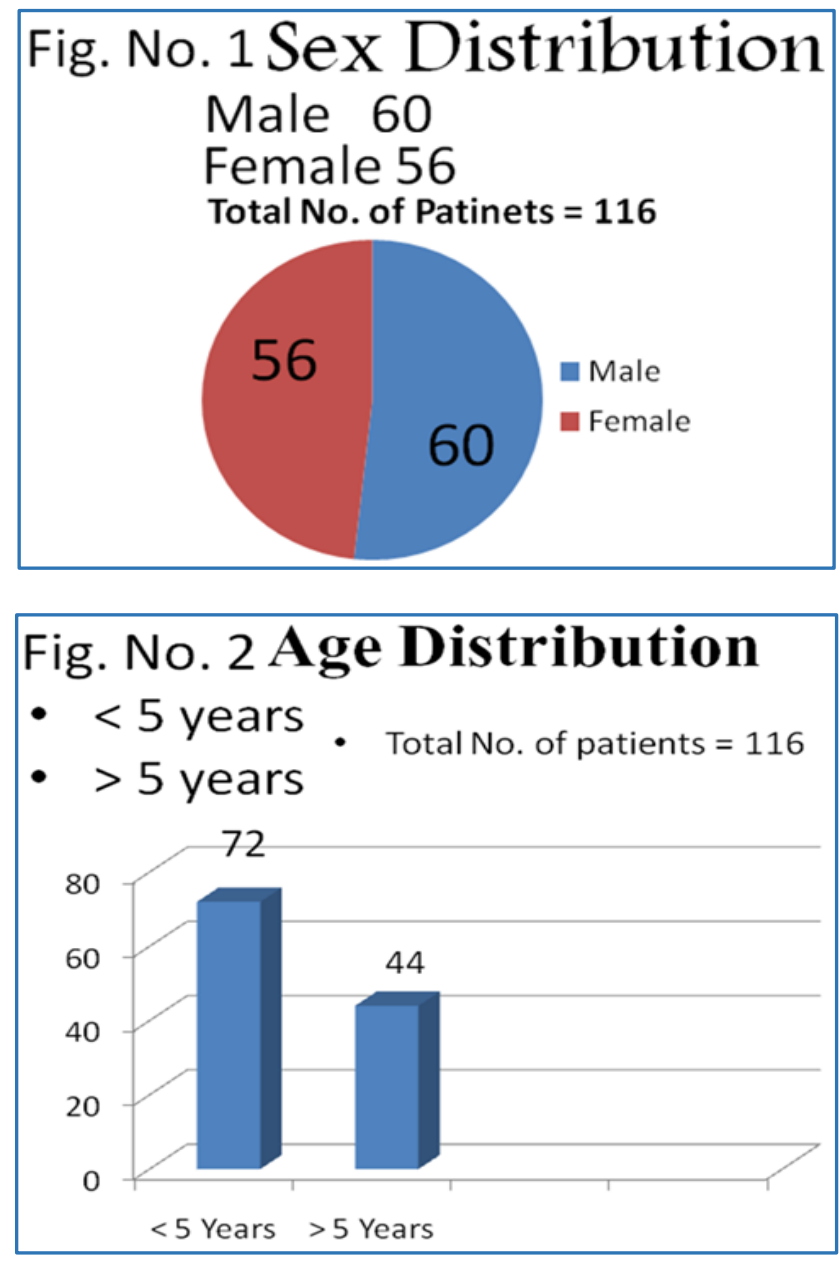

\section{DISCUSSION}

Adults and older children usually give a history of foreign body while presenting in ENT or Paediatric Department. But younger children are brought to the hospital by anxious parents or relatives. Foreign bodies may vary widely in shape, size, and composition and the symptoms may range from asymptomatic to acute life threatening condition.

In our study, Majority (72) were below 5 years of age and 44 were above 5 years. Youngest child was 6 months old and the eldest was of 14 years, similar to results found in many other studies. $^{5-9}$ This may be due to the tendency of young children to lodge objects into the natural orifices of body, accidentally or intentionally. Foreign body ingestion is a common problem. The most frequently swallowed foreign 
body in children include coins and metallic foreign bodies (parts of playing objects), and meat bones (chicken bone/fishbone/mutton/buffalo meat) are common in adults and elderly. ${ }^{9} 10$ In our study, majority $(62.06 \%, 72)$ of children reported with foreign body in throat or oesophagus which included coin in 50 cases followed by battery in 16 cases and chicken bone in 3 , and the most common site of lodgement was the upper end of oesophagus. Such patients come in clusters, especially during religious festivals. Coin was the most common FB in the oesophagus in children in our study, which is similar to various other studies.8-10 This may be due to the fact that the coins are often handed to younger children and they accidentally swallow because of their tendency to put things into the mouth, inadequate control of deglutition, and shouting or crying while playing or eating. Plain X-ray of neck and chest was found to be a costeffective radiologic investigation for evaluation of foreign bodies in the throat and oesophagus similar to the observations made by Sarkar et al. ${ }^{1}$ Direct laryngoscopy was occasionally useful in the evaluation and removal of foreign body in the oropharynx and hypopharynx. Foreign bodies from the digestive tract are usually removed by rigid oesophagoscopy but in certain cases flexible upper gastrointestinal endoscopy may be required. Moreover, it helps to detect the site of impaction especially in patients with severe cervical spondylosis where neck extension is difficult.

Similar to the findings reported by Sarkar et al, the ear was the next most common site for foreign bodies in young children in our study, who not only insert objects in their ears but also into the ears of their siblings and friends. ${ }^{1}$ Common ear foreign bodies include cotton wool, bean, bead, paper/plastic, eraser, insect, paddy seed, and popcorn kernel.1,11 Patients usually present with earache, aural fullness, or ear discharge but occasionally it may be asymptomatic and found incidentally during routine otoscopic examination. ${ }^{12}$ A total of $28(24.13 \%)$ children reported with history of foreign body in ear which included pea in 8 cases, eraser in 8 cases followed by pebbles in 4 cases and 2 cases each of remote button, maize seed and a peanut which is in corroboration with other studies.111 No foreign body was detected in 2 cases. Jobson Horne probe, Tilley forceps, Foreign body hook, crocodile forceps, syringing or suctioning are used to remove foreign body from ear. Examination with the help of a microscope can help in locating the foreign body and its removal especially in noncooperative children and in presence of concomitant otitis externa. This in fact minimises the trauma to external auditory canal and tympanic membrane. Non-hygroscopic foreign bodies can be removed successfully by syringing. In presence of aural discharge, foreign bodies can be removed from ear by applying suction. ${ }^{13}$ In present study, Jobson Horne probe and ear hook were used to remove foreign bodies from ear.

We observed a total of $8(6.89 \%)$ cases each of foreign body in nose and bronchus. In bronchus, bits of almond and berry fruit were detected in 3 cases each and a small plastic whistle and a small plastic pen rear cap was detected in one case each all of which were removed by rigid bronchoscopy. There are many defence mechanisms to prevent the foreign body aspiration. Epiglottis and arytenoids cartilage block the airway while swallowing to prevent entry of food material into the air way. Similarly, vocal cords go into severe spasm as soon as any object approaches them. A highly sensitive cough reflex with afferent signals from larynx, trachea and proximal tracheobronchial tree also helps in preventing entry of any foreign body into the airway. But despite of these preventive mechanisms, foreign body aspiration in airway is seen quite frequently especially in children. ${ }^{14}$ Children less than or equal to 4 years of age are more prone to develop foreign body aspiration due to the lack of molar teeth and proper swallowing coordination. ${ }^{15}$ In our study, in six out of the eight bronchial foreign body cases, foreign bodies were found in right main bronchus which is similar to the observations made by Eren et al ${ }^{16}$ who reported $52 \%$ of airway foreign bodies in right main bronchus. In a child sitting in upright posture, right-sided airways are direct entries from trachea. Left main bronchus is smaller in size and a bit angulated, thus making it easy for a foreign body to enter right main bronchus. Similar to the findings reported by many other studies in our study, six out of eight cases presented with sudden onset of cough, dyspnoea, wheezing and diminished air entry on the affected side.17-19 One case with plastic whistle in right main bronchus presented with sudden onset of cough and localised whistling sound on right side. X-ray chest showed hyperinflation on affected side in five out of eight cases. Virtual bronchoscopy helped in detecting location of foreign body in 3 cases.

In nose, 3 cases each of button, peanut, and 2 of watch cell were observed similar to the observations made by other studies. ${ }^{1,20}$ Anterior rhinoscopy was done in all the cases to detect and remove these foreign bodies. Unilateral, foulsmelling, purulent nasal discharge in children must be regarded as due to foreign body until proved otherwise.1,21 Introduction of foreign body in the nostrils diminishes significantly with growth and cognitive development. In adults, it is encountered only in patients with psychiatric disorders.

Foreign body in the nose or ear is usually unilateral, although it can be bilateral. Sometimes there can be multiple ear or nose foreign bodies as well. We saw a child with two peanuts in one nostril.

\section{CONCLUSION}

In children, foreign bodies in throat and oesophagus were found more frequently than in ear and nose, contrary to the results shown by some studies that foreign bodies are more in ear and nose in children and the throat was the most common site of foreign bodies in adults and elderly people. Most of the nasal and aural foreign bodies can be easily removed in the emergency room or outdoor patient department. Parents or caretakers should not allow children to play with coins or other small objects to prevent the risk of foreign body ingestion or insertion. Prevention is the key element in such type of accidents and injuries. Shlizmer et $\mathrm{a}^{22}$ observed that well-defined public education programs could lead to prevention, hence more stress should be given to the education of care givers. Mass media should be utilised to draw attention and disseminate awareness amongst masses regarding preventive measures. ${ }^{23}$ 


\section{REFERENCES}

[1] Sarkar S, Roychoudhury A, Roychaudhuri BK. Foreign bodies in ENT in a teaching hospital in Eastern India. Indian J Otolaryngol Head Neck Surg 2010;62(2):11820.

[2] Carney AS, Patel N, Clarke R. Foreign bodies in the ear and the aerodigestive tract in children. Scott-Brown's Otorhinolaryngology. Head and Neck Surgery. $7^{\text {th }}$ edn. London, UK: Edward Arnold 2008:1184-93.

[3] Shrestha I, Shrestha BL, Amatya RC. Analysis of ear, nose and throat foreign bodies in Dhulikhel hospital. Kathmandu Univ Med J (KUMJ) 2012;10(38):4-8.

[4] Passàli D, Lauriello M, Bellussi L, et al. Foreign body inhalation in children: an update. Acta Otorhinolaryngol Ital 2010;30(1):27-32.

[5] Banerjee S. Concept of foreign body - its past and present. Indian J Otolaryngol Head Neck Surg 1999;51(Suppl 1):23-30.

[6] Das SK. Aetiological evaluation of foreign bodies in the ear and nose. J Laryngol Otol 1984;98(10):989-91.

[7] Higo R, Matsumoto Y, Ichimura K, et al. Foreign bodies in the aerodigestive tract in pediatric patients. Auris Nasus Larynx 2003;30(4):397-401.

[8] Ray R, Dutta M, Mukherjee M, et al. Foreign body in ear, nose and throat: experience in a tertiary hospital. Indian J Otolaryngol Head Neck Surg 2014;66(1):1316.

[9] Adhikari P, Shrestha BL, Baskota DK, et al. Accidental foreign body ingestion: analysis of 163 cases. Int Arch Otorhinolaryngol 2007;11(3):267-70.

[10] Pokharel R, Adhikari P, Bhusal CL, et al. Oesophageal foreign bodies in children. JNMA J Nepal Med Assoc 2008;47(172):186-8.

[11] Ansley JF, Cunningham MJ. Treatment of aural foreign bodies in children. Pediatrics 1998;101(4 Pt 1):63841.

[12] DiMuzio J, Deschler DG. Emergency department management of foreign bodies of the external ear canal in children. Otol Neurotol 2002;23(4):473-5.
[13] Parajuli R. Foreign bodies in the ear, nose and throat: an experience in a tertiary care hospital in central Nepal. Int Arch Otorhinolaryngol 2015;19(2):121-3.

[14] Pak MW, van Hasselt CA. Foreign bodies in children's airways: a challenge to clinicians and regulators. Hong Kong Med J 2009;15(1):4-5.

[15] Reilly JS, Cook SP, Stool D, et al. Prevention and management of aerodigestive foreign body injuries in childhood. Pediatr Clin North Am 1996;43(6):1403-11.

[16] Eren S, Balci AE, Dikici B, et al. Foreign body aspiration in children: experience of 1160 cases. Ann Trop Paediatr 2003;23(1):31-7.

[17] Shivakumar AM, Naik AS, Prashanth KB, et al. Tracheobronchial foreign bodies. Indian $\mathrm{J}$ Pediatr 2003;70(10):793-7.

[18] Chiu CY, Wong KS, Lai SH, et al. Factors predicting early diagnosis of foreign body aspiration in children. Pediatr Emerg Care 2005;21(3):161-4.

[19] Asif M, Shah SA, Khan F, et al. Analysis of tracheobronchial foreign bodies with respect to sex, age, type and presentation. J Ayub Med Coll Abbottabad 2007;19(1):13-5.

[20] Kalan A, Tariq M. Foreign bodies in the nasal cavities: a comprehensive review of the aetiology, diagnostic pointers and therapeutic measures. Postgrad Med J 2000;76(898):484-7.

[21] Kadish HA, Corneli HM. Removal of nasal foreign bodies in the pediatric population. Am J Emerg Med 1997;15(1):54-6.

[22] Shlizerman L, Ashkenazi D, Mazzawi S, et al. Foreign body aspiration in children: ten-years of experience at the Ha'Emek Medical Center. Harefuah 2006;145(8): 569-71, 631.

[23] Brkić F, Umihanić S. Tracheobronchial foreign bodies in children. Experience at ORL clinic Tuzla, 1954-2004. Int J Pediatr Otorhinolaryngol 2007;71(6):909-15. 